\title{
Creative Research Communication - Theory and Practice
}

Book

Reviewed by

Abstract

Keywords
WILKINSON, C. AND WEITKAMP, E. (2016).

Creative Research Communication - Theory and Practice.

MANCHESTER, U.K.: MANCHESTER UNIVERSITY PRESS
This article aims to present a critical analysis of the book entitled "Creative Research Communication - Theory and Practice", written by Clare Wilkinson and Emma Weitkamp (Manchester University Press, 2016). We aim to present the structure of the book, highlighting its strengths and successes. Although some chapters focus on the UK, the book offers a wide range of examples of practical activities for the communication of research of global interest and provides very useful tips. Ethical issues and the importance of evaluation, of how to do carry out such evaluation and dissemination, are also presented in an inspiring way. Well-written and objective, the book is a must-read for anyone who works, or aspires to work, in the field of public engagement with research.

Professionalism, professional development and training in science communication; Science communication: theory and models

The book entitled "Creative Research Communication - Theory and Practice" (Manchester University Press, 2016) discusses different ways of engaging the public with science - or research, a term used throughout the book. Knowing where the authors come from is already a clue as to the contents of the book: Clare Wilkinson and Emma Weitkamp are Associate Professors of Science Communication at the University of the West of England in Bristol, England.

The book is divided into three parts.

The introduction presents the context of public engagement, addressing historical roots and some current trends. The second part deals with different approaches to public engagement. The third part presents ethical issues and ways in which communication can contribute to the impact of the research itself.

The book interested me from the very beginning.

As a science communicator and a researcher interested in themes on science and society, and mostly through my role in training new generations, I highly value books like this, which are few, especially in Latin America, where I work. 
Its well-written and objective text is a strength of the publication and it has certainly been useful to people who want to get to know the field better. At the end of each chapter there are an overview and additional readings. In my view, the fact that the first part of the publication is particularly focused on the UK should not be taken as a criticism.

I believe it is very important for the reader to know the route that public engagement has taken in that country and understand its success and important actions, such as the emblematic document entitled "The Public Understanding of Science" issued by the Royal Society of Science in 1985, better known as the Bodmer Report. This publication played a crucial role in encouraging the scientific community to engage with the public (whether this is a coincidence or not, it is precisely in that decade that the scientific community became more involved in science communication in Latin America).

It is inspiring and makes one feel a bit envious when going through the excerpts from the book that addresses the institutionalisation of public engagement in the UK.

It is worth highlighting that the UK has also been the scene of episodes that are regarded as "failures" of public engagement, such as the episode of nuclear waste in the Lakes and the mad cow disease, which have been documented and on which there are interesting reflections, being systematically addressed in another part of the world, where there are courses in science dissemination.

The historical part of the book gives a brief overview (perhaps a little too short, yet objective) on the history of public engagement since the 17th century, discussing aspects such as scientists engaged in science dissemination, museums and the professional training in the field.

The first part of the book also includes a few pages that are intended to remind the reader of the importance of thinking about the audiences we communicate to although this may seem obvious to already initiated readers of JCOM, many communicators end up forgetting to keep this in mind, which can lead to reduced success or even failure of some initiatives.

I was actually patient and very happy to read a book that deals with the reality of the UK.

However, I was impressed to notice that the second and third part of the book had a global perspective, with an approach that certainly fits perfectly to the reality of different countries and cultures.

The authors present a great variety of initiatives, with examples of projects and practical tips very useful to those who want to explore the field of public engagement or to delve into their main issues.

A book's success is the division of these initiatives into thematic chapters (face-to-face activities, art, digital world, social media, political theme, research funded by crowd-source mechanisms), which allows for a more specific discussion for each one of the themes. 
In the third part, the authors discuss fundamental aspects such as impact and evaluation, providing very useful tips as well. The presentation of possible evaluation methods, with their strengths and weaknesses, is another highlight of the book.

At the end, the authors discuss ethical issues related to the communication of research, including how to engage participants ethically, informed consent procedures, and reflections on how to collect, use, and store data.

At least in Latin America, the discussion about ethics of research has grown exponentially in the last decade - but not when we think of communicating research, which has made me consider it as a chapter that deserves particular attention.

The last chapter, which discusses the fundamental role of dissemination, is not less important. The authors point out that academics may be used to communicating the results of their studies to their peers, but they do not always consider communicating the success (or failure) of new approaches to communication (p. 256).

In order to fill this gap, the authors give advice about how to make a good report, about some academic journals in English and some of the top research communication conferences in the world.

In the end, there are about 400 bibliographical references that - although focused on English texts - are a fundamental reading resources for further study in the field. In summary, it is must-read book for those who work, or aspire to work, in the field of public engagement in research.

\section{Translated by Sabina Brusemini}

Luisa Massarani is a Brazilian science communicator and Executive Director of the Red de Popularización de la ciencia y la tecnología en América Latina y el Caribe (Latin American and Caribbean Network for the Popularisation of Science and Technology) (RedPOP). She organizes practical and academic activities in science communication. She coordinates the Master in Communication of Science, Technology and Health, established in 2016 at the Casa de Oswaldo Cruz, Fundação Oswaldo Cruz, in Brazil. She is the coordinator for Latin America and the Caribbean of 101 SciDev.Net (www.scidev.net). She is the recipient of the Brazilian Award for Science Communication "Premio José Reis de Divulgação Científica", in 2016, and the literature Brazilian Award Jabuti, in 2017. E-mail: luisa.massarani@fiocruz.br.

\section{How to cite}

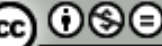

Massarani, L. (2017). 'Creative Research Communication - Theory and Practice'. JCOM 16(05), R03_en.

This article is licensed under the terms of the Creative Commons Attribution - NonCommercial - NoDerivativeWorks 4.0 License. ISSN 1824-2049. Published by SISSA Medialab. jcom.sissa.it 